\title{
Therapeutics in Allergic Contact Dermatitis, when Avoidance Fails
}

\section{Michael P. Sheehan, MD}

\author{
Address \\ 360 Plaza Drive, Suite C, Columbus, IN 47201, USA \\ Email:mpsheeha@iupui.edu
}

Published online: 17 September 2014

(C) Springer International Publishing AG 2014

Keywords Allergic contact dermatitis - Type IV hypersensitivity - Contact hypersensitivity - Treatment - Management . Dermatitis - Eczema

\section{Opinion statement}

Patch testing is the gold standard for the diagnosis of allergic contact dermatitis (ACD). The management of patients with ACD centers on allergen avoidance. With avoidance of future exposures, the signs and symptoms of ACD should resolve. However, in practice there will be some patients that do not achieve adequate control with avoidance alone. Unfortunately, there is a dearth of literature available to guide the next steps in management of these patients with recalcitrant dermatitis. A practical approach includes reviewing the relevance of positive patch test results, considering patient adherence and ability to comply with avoidance, addressing the potential for multifactorial disease, and in select cases employing adjuvant topical and/or systemic treatment.

Key points

1. Allergic contact dermatitis is a type IV (delayed) hypersensitivity reaction presenting clinically as dermatitis.

2. Patch testing is the gold standard for the diagnosis of allergic contact dermatitis.

3. Allergen avoidance protocols are the primary management tools used in treating patients with allergic contact dermatitis.

4. In patients with suboptimal clinical outcomes despite appropriate avoidance, the potential for multifactorial disease should be addressed and pharmacologic adjuvants for symptomatic control should be considered.

\section{Introduction}

Allergic contact dermatitis (ACD) is a type IV (delayed) hypersensitivity reaction. It is both host and hapten specific. The clinical presentation of ACD is that of an eczematous eruption, which may be acute, subacute, or chronic. In acute cases, the skin may show erythema, microvesiculation, and edema. The rash of poison ivy is the prototypical example of an acute ACD. Chronic cases tend to feature more dryness, scaling, and thickening of 
the skin. The infraumbilical plaque of nickel ACD related to belt buckle exposure is a commonly noted example of chronic ACD.

The primary means of diagnosing contact allergy is patch testing and the first line of management is allergen avoidance. By definition, contact allergy should resolve with complete avoidance of the driving contactant. However, clinical experience shows that not all patients with positive patch test results will improve with avoidance recommendations.

The persistence of signs and symptoms at follow-up raise several questions. Are the positive reactions noted on patch testing relevant to the patient's current dermatitis? Did the patient receive and understand adequate education to allow for complete allergen avoidance? Did the patient consistently adhere to the recommended avoidance protocol? Are there routes of allergen exposure that the patient and physician are not aware of? Is complete avoidance a reasonable expectation? Are the patient's signs and symptoms in part or fully the result of an etiology other than ACD?

It has been suggested that when sufficient avoidance protocols fail, a practical next step in management is to redirect efforts under the premise of "dermatitis of unclear etiology" [1]. Taking this step back in clinical assessment allows the physician to consider the above questions while adjuvant therapeutic measures are considered.

\section{Determining relevance of positive reactions}

Evaluating the relevance of a positive patch test reaction is often considered the most difficult and intricate part of the patch testing process [2, 3]. Detailed narratives for standard allergens are available through the American Contact Dermatitis Society's Contact Allergen Management Program (CAMP). Commercial suppliers of allergens for patch testing also provide allergen information. These educational materials on the occurrence of each allergen in the environment should be reviewed with the patient while determining the relevance of positive reactions. The patient's history should be explored, to determine if exposure is known or plausible, and to determine whether the current site, course, and history of relapses are consistent with the known or potential exposure. It is important to try and separate out positive test results that are not currently relevant and represent past sensitization, from those that are associated with the presenting dermatitis.

\section{Avoidance protocols}

It is important to consider the ability and desire of the patient to strictly adhere to avoidance. Jamil and colleagues recently reviewed the ability of patients to recall their patch test results over a 10-year period. They found that while $79 \%$ of patients recalled that they had a positive result, only $29 \%$ of patients correctly recalled the actual allergen. It was also noted that as the number of positive reactions increased, patient recall decreased [ $4 \bullet$ ]. These findings highlight the importance of patient education. If patients do not understand their condition and the nature of the environmental triggers, it will be very difficult, if not impossible, for them to sufficiently avoid the necessary contactants.

Information on personal protective equipment is a critical part of avoidance protocols. For example, patients with ACD of the hands will often fail to improve if they do not understand and employ appropriate glove use.

While the therapeutic effects of diet in contact dermatitis is controversial, systemic avoidance protocols may be required in some patients. This is best 
established in patients that are highly reactive to nickel or balsam of Peru. In these cases, dietary restriction has been noted to translate into improved clinical outcome.

\section{Considering multifactorial disease}

If ACD shows an unusually recalcitrant course despite adequate allergen avoidance, the correctness of the diagnosis must be questioned. Dermatitis is a clinical phenotype that may be the result of exogenous factors, endogenous factors, or both. The term "hybrid dermatitis" has been used to describe patients in whom there are both endogenous and exogenous driving factors. When managing patients with ACD showing suboptimal clinical outcomes, it is important to consider potential confounding factors or alternative (or potentially co-existing) diagnoses such as irritant contact dermatitis, atopic dermatitis, seborrheic dermatitis, dyshidrosis, stasis dermatitis, xerosis, nummular dermatitis, and neurodermatitis.

\section{Pharmacologic adjuvants for symptomatic control}

\section{Antihistamines}

Antihistamines are generally well tolerated and an often overlooked adjuvant therapy in the management of ACD. First generation H1 antagonists such as hydroxyzine lend not only pruritus relief, but also a degree of sedation, which when dosed in the evening can help restore much needed lost sleep related to severe itching. The less sedating second-generation $\mathrm{H} 1$ antagonists such as loratadine or cetirizine are more suited for daytime dosing.

\section{Immunomodulatory and anti-proliferative drugs}

\section{Topical and systemic corticosteroids}

Topical and systemic corticosteroids are the mainstay in the symptomatic treatment of eczematous reactions including ACD. Corticosteroids inhibit T cell activation and leukocyte migration.

Topical hydrocortisone was first introduced in 1950 and first described by Sulzberger et al. for the treatment of skin diseases in 1951[5]. Today, topical corticosteroids are the most commonly prescribed topical medications in the outpatient setting [6,7]. Topical corticosteroids are grouped based on their relative potency into one of seven groups, with class-I being super potent and class-VII being the least potent (Table 1) [8]. Structural classification is another method of categorization for corticosteroids, with the five-class system being the most commonly used (Table 2) [9], and an alternative three-class system has been recently introduced in which groups are based on reactive properties, as well as structural methylation and halogenation [57].

There are several studies evaluating the effectiveness of various corticosteroids in the management of $\mathrm{ACD}$, demonstrating good-quality evidence for the use of moderate to high-potency steroids for symptomatic management of ACD [10]. Fluticasone $0.05 \%$ propionate has been shown to be effective in reducing nickel-induced contact allergy [11]. A similar study in patients with nickelinduced contact allergy was able to show that clobetasone butyrate $0.05 \%$ 


\section{Table 1. Topical corticosteroids}

\begin{tabular}{|c|c|c|}
\hline \multicolumn{3}{|l|}{ Class-I Superpotent } \\
\hline \multirow[t]{3}{*}{ Clobetasol propionate $0.05 \%$} & Clobex & Spray \\
\hline & Olux, Olux-E & Foam \\
\hline & Temovate & Ointment, Cream, Gel, Solution \\
\hline Betamethasone dipropionate $0.05 \%$ & Diprolene & Ointment, Lotion, Gel \\
\hline Halobetasol propionate $0.05 \%$ & Ultravate & Ointment, Cream \\
\hline Fluocinonide $0.01 \%$ & Vanos & Cream \\
\hline \\
\hline \multirow[t]{2}{*}{ Betamethasone dipropionate $0.05 \%$} & Diprolene AF & Cream \\
\hline & Diprosone & Ointment \\
\hline Desoximetasone $0.25 \%, 0.05 \%$ & Topicort & Ointment, Cream, Gel, Spray \\
\hline \multirow[t]{2}{*}{ Diflorasone diacetate $0.05 \%$} & Psorcon E & $\begin{array}{l}\text { Emollient Ointment, Emollient } \\
\text { Cream }\end{array}$ \\
\hline & Apexicon $\mathrm{E}$ & Emollient Cream \\
\hline Halocinonide $0.1 \%$ & Halog & Ointment, Cream, Solution \\
\hline Fluocinonide $0.05 \%$ & Lidex & Ointment, Cream, Gel, Solution \\
\hline \multicolumn{3}{|l|}{ Class-III Upper Mid Potency } \\
\hline Amcinonide $0.1 \%$ & Cyclocort & Cream, Lotion \\
\hline Betamethasone dipropionate $0.05 \%$ & Diprosone & Cream \\
\hline Betamethasone valerate $0.12 \%$ & Luxiq & Foam \\
\hline Betamethasone valerate $0.1 \%$ & Valisone, Betatrex & Ointment \\
\hline Diflorasone diacetate $0.05 \%$ & Psorcon & Cream \\
\hline Fluticasone propionate $0.005 \%$ & Cutivate & Ointment \\
\hline Mometasone furoate $0.1 \%$ & Elocon & Ointment \\
\hline \multirow[t]{2}{*}{ Triamcinolone acetonide $0.5 \%$} & Kenalog & Ointment \\
\hline & Aristocort HP & Cream \\
\hline Triamcinolone acetonide $0.1 \%$ & Aristocort A & Ointment \\
\hline \multicolumn{3}{|l|}{ Class-IV Mid Potency } \\
\hline Clocortolone pivalate $0.1 \%$ & Cloderm & Cream \\
\hline Flurandrenolide $0.05 \%$ & Cordran & Ointment \\
\hline Fluocinolone acetonide $0.025 \%$ & Synalar & Ointment \\
\hline Hydrocortisone valerate $0.2 \%$ & Westcort & Ointment \\
\hline Mometasone furoate $0.1 \%$ & Elocon & Cream, Lotion, Solution \\
\hline Triamcinolone acetonide $0.1 \%$ & Kenalog & Cream, Lotion, Spray \\
\hline \multicolumn{3}{|l|}{ Class-V Lower Mid Potency } \\
\hline $\begin{array}{l}\text { Betamethasone diproprionate } \\
0.05 \%\end{array}$ & Diprosone & Lotion \\
\hline Betamethasone valerate $0.1 \%$ & Beta-Val, Betatrex, Valisone & Cream \\
\hline Desonide $0.05 \%$ & Desowen, Desonate & Ointment, Gel \\
\hline Fluocinolone acetonide $0.025 \%$ & Synalar & Cream \\
\hline Flurandrenolide $0.05 \%$ & Cordran & Cream, Lotion \\
\hline Fluticasone propionate $0.05 \%$ & Cutivate & Cream, Lotion \\
\hline Hydrocortisone butyrate $0.1 \%$ & Locoid & Ointment, Cream, Solution \\
\hline Hydrocortisone valerate $0.2 \%$ & Westcort & Cream \\
\hline Triamcinolone acetonide $0.1 \%$ & Kenalog & Lotion \\
\hline $\begin{array}{l}\text { Triamcinolone acetonide } 0.025 \% \\
\text { Class-VI Mild }\end{array}$ & Kenalog & Ointment \\
\hline Alclometasone dipropionate $0.05 \%$ & Aclovate & Ointment, Cream \\
\hline
\end{tabular}




\begin{tabular}{|c|c|c|}
\hline Betamethasone valerate $0.1 \%$ & Beta-Val, Valisone & Lotion \\
\hline Desonide $0.05 \%$ & Verdaso, Tridesilon, DesOwen, Lokara & Foam, Cream, Lotion \\
\hline Fluocinolone acetonide $0.01 \%$ & Synalar, Derma-Smoothe FS & Cream, Solution, Scalp Oil \\
\hline $\begin{array}{l}\text { Triamcinolone acetonide } 0.025 \% \\
\text { Class-VII Least Potent }\end{array}$ & Kenalog, Aristocort & Cream, Lotion \\
\hline Hydrocortisone $1 \%$ & Cetacort, Cortaid, Hytone Nutracort, Synacort & Ointment, Cream, Lotion, Spray \\
\hline Hydrocortisone $2.5 \%$ & Hytone & Ointment, Cream, Lotion, Solution \\
\hline
\end{tabular}

cream showed a better response when compared to hydrocortisone $1 \%$ cream and no treatment [12]. Clobetasol propionate $0.05 \%$ ointment has also been shown to effectively ameliorate the signs and symptoms of experimentally induced Rhus dermatitis [13].

While topical corticosteroids clearly show utility in management of ACD, there are mixed results as to their utility in irritant contact dermatitis [14]. There is good evidence that lipid-rich moisturizers alone may be as effective in the management of pure irritant contact dermatitis [10].

Severe widespread ACD may necessitate a course of systemic corticosteroids. Despite the often rapid and dramatic improvement with systemic corticosteroids, the potential for multiple systemic side effects and high recurrence rate with drug cessation limit therapy.

\section{Topical and systemic calcineurin inhibitors}

Topical and systemic calcineurin inhibitors may also be considered for management of recalcitrant ACD. Pimecrolimus $1 \%$ cream and tacrolimus $0.03 \%$ and $0.1 \%$ ointment are both topical immunosuppressive agents capable of inhibiting T-lymphocyte and dendritic cell activation. Both have been shown to inhibit both ICD and ACD [15]. They offer a unique topical option for steroid sparing treatment of ACD. Katsarou et al. evaluated the efficacy of tacrolimus

\section{Table 2. Topical corticosteroid structural classification}

- Class A - Hydrocortisone type (Cross-Reacts with Class D2)

Hydrocortisone, Hydrocortisone acetate, Cortisone acetate, Tixocortol-21- pivalate, Prednisolone, Methylprednisolone, and Prednisone

- Class B - Triamcinolone acetonide type (Cross-Reacts with Class D2)

Triamcinolone acetonide, Triamcinolone alcohol, Amcinonide, Budesonide, Desonide, Fluocinonide, Fluocinolone acetonide, and Halcinonide

- Class C - Betamethasone type (Hypoallergenic Class)

Desoximetasone, Clocortolone pivalate, Betamethasone, Betamethasone sodium phosphate, Dexamethasone, Dexamethasone sodium phosphate, and Fluocortolone

- Class $\mathbf{D}_{1}$ - Betamethasone dipropionate type

Clobetasol-17-propionate, Betamethasone dipropionate, Diflorasone diacetate, Betamethasone Valerate, Clobetasone butyrate, Fluticasone propionate, Mometasone furoate, Alclometasone dipropionate

- Class $\mathbf{D}_{2}$ - Methylprednisolone aceponate type (Cross Reacts with Class A \& B)

Hydrocortisone-17-butyrate, Hydrocortisone-17-valerate, Hydrocortisone buteprate, Prednicarbate

*Adapted from Jacob SE, Steele T. Corticosteroid classes: A quick reference guide including patch test substances and cross-reactivity. J Am Acad Dermatol. 2006;54(4):723-727 
$0.1 \%$ ointment in allergic contact hand eczema. In a prospective randomized study, they compared tacrolimus $0.1 \%$ ointment to mometasone furoate $0.1 \%$ ointment in patients with chronic hand eczema and a positive patch test, and found that the clinical response was similar in both groups [16•]. Topical tacrolimus has also been used with success in the management of ACD of the eyelids [17], and has shown the ability to suppress nickel-elicited ACD [18, 19]. In a study that compared pimecrolimus $1 \%$ cream, tacrolimus $0.1 \%$ ointment, clobetasol propionate $0.05 \%$ ointment, and triamcinolone acetonide $0.1 \%$ ointment, the four agents were found to be equal in their ability to suppress experimentally induced nickel contact dermatitis [20]. Similarly, topical pimecrolimus has been reported as a successful treatment for ACD with genital involvement [21]. However, while both tacrolimus and pimecrolimus are felt to be equipotent in suppressing the elicitation phase of ACD, pimecrolimus may be less effective in preventing the sensitization phase [22, 23]. This difference does not appear to have clinical relevance. In addition to suppression of Tlymphocyte and dendritic cell activation, topical calcineurin inhibitors have been shown to have anti-pruritic effects that have been attributed to the inhibition of inflammatory cytokines. Studies have shown that sensory nerve fibers show a release of neuropeptides and degranulation of mast cells mediated by tacrolimus and pimecrolimus similar to that seen with capsaicin [24]. This may explain not only the antipruritic effects, but also the potential adverse effects; some patients note describing a burning sensation or pruritus with treatment initiation.

Cyclosporine is a systemic calcineurin inhibitor that is often effective at inducing a rapid resolution of the signs and symptoms of ACD. This can be particularly useful in patients with severe generalized dermatitis needing to undergo evaluation with patch testing, but in whom other measures have failed to clear their dermatitis sufficiently to allow testing [25]. The effectiveness of cyclosporine in some cases of ACD is illustrated by its effectiveness in parthenium dermatitis, which is ACD driven by the weed Parthenium hysterophorus. Parthenium dermatitis is characteristically refractory in nature. Lakshmi et al. reported two patients with parthenium ACD who showed a dramatic improvement in refractory pruritus by day 10 of treatment with cyclosporine [26]. Cyclosporine has also been used to treat chronic hand dermatitis, but with somewhat underwhelming results [27]. More information on the use of cyclosporine for refractory dermatitis can be drawn from the literature with respect to the management of severe atopic dermatitis (AD). Here, cyclosporine is considered a first-line systemic option for short-term control of moderate to severe $\mathrm{AD}$ [28]. Cyclosporine has been shown to be effective in the systemic management of moderate to severe AD in several randomized clinical trials. A mean clinical improvement in severity between $53 \%$ and $95 \%$ was noted in different clinical severity scores after short-term treatment (10 days to 8 weeks) [29-32]. Superior efficacy to prednisolone, IVIg, and NB-UVB has also been noted in head-to-head studies [28].

\section{Azathioprine}

Azathioprine is a systemic immunosuppressive agent. It was originally manufactured as a pro-drug for 6-mercaptopurine in 1957 to treat the rapidly proliferating cells of cancer by inhibiting DNA synthesis. This effect on 
proliferating cells was noted to have the added benefit of a fairly selective therapeutic option for disease processes in which $\mathrm{T}$ cell and B cell overactivity was a problem. The benefit of azathioprine in dermatitic processes is well known, and it is considered a second-line systemic option for moderate to severe AD [28].

Azathioprine undergoes a complex metabolism involving the enzyme thiopurine methyl transferase (TPMT). While a large majority of patients show high activity levels of TPMT, one in 300 patients will have very low levels. These patients will have markedly increased levels of 6thioguanine metabolites and an increased risk of pancytopenia. This variation must be kept in mind when dosing azathioprine, and enzyme levels are checked prior to starting therapy.

The majority of the literature regarding ACD and azathioprine is derived from patients with Parthenium dermatitis. De and colleagues recently reviewed the safety and efficacy of azathioprine versus methotrexate (as a steroid sparing agents) for patients with ACD driven by Parthenium hysterophorus. They noted that both azathioprine and methotrexate are effective and safe steroid-sparing agents, but that methotrexate may have achieved a more rapid control [33]. Azathioprine has also been noted to be as effective, but with less adverse effects when compared to systemic corticosteroids (betamethasone) in the management of Parthenium dermatitis [34]. It has also been suggested that weekly pulse dosing of azathioprine may be effective for ACD [35].

Methotrexate is a strong competitive antagonist of the enzyme dihydrofolate reductase, which is the enzyme responsible for conversion of dihydrofolate to tetrahydrofolate. Tetrahydrofolate is a necessary co-factor in the production of thymidylate and purine nucleotides needed for DNA and RNA synthesis. The net result is inhibition of cell division, which affects the proliferation of lymphocytes, thereby yielding immunosuppressive and anti-inflammatory effects.

Similar to azathioprine, much of the working knowledge of methotrexate use in severe refractory ACD is derived from the AD literature. Schram et al. conducted the first randomized controlled trial in 2011 to demonstrate efficacy of methotrexate in treatment of $\mathrm{AD}$. They performed a study of 42 adult $\mathrm{AD}$ patients randomized to either methotrexate $10 \mathrm{mg}$ weekly, or azathioprine $1.5 \mathrm{mg} / \mathrm{kg} / \mathrm{day}$ for 12 weeks. Patient dosing was titrated upward until either $25 \%$ reduction in disease activity was achieved, or the maximum dose allowed in the study (22.5 mg/week methotrexate, $2.5 \mathrm{mg} / \mathrm{kg} /$ day azathioprine) was reached. The two medications performed similarly in a number of disease severity measures, including SCORAD (SCORing Atopic Dermatitis), IgE (immunoglobulin E), EASI (Eczema Area Severity Index), and serum TARC (Thymus and activation-regulated chemokine). Patients treated with methotrexate showed a significant improvement of $42 \%$ in SCORAD at 12 weeks, whereas patients treated with azathioprine showed a $39 \%$ improvement [36, 37]. Sharma published the results of 16 patients treated with methotrexate who were diagnosed with Parthenium dermatitis, confirmed by patch or photopatch testing. These patients were refractory to treatment with potent topical corticosteroids. Patients received methotrexate $15 \mathrm{mg} /$ week with folic acid $5 \mathrm{mg} /$ daily. Only seven patients followed up $>6$ months. The majority of the patients who 
followed up (six) noted an early improvement with a decrease in disease severity after 1 month [38].

Methotrexate has also been reported to show partial or complete clearance in chronic dyshidrotic eczema in five patients treated with doses ranging from 12.5 to $22.5 \mathrm{mg} /$ week [39].

\section{Mycophenolate mofetil and mycophenolic acid}

Mycophenolate mofetil (MMF) is an immunosuppressant originally isolated as a fermentation product of Penicillium stoloniferum in 1986 [40••]. It is typically well tolerated and felt to be less toxic than azathioprine, and more acceptable for long-term use than cyclosporine. The most common adverse effect is dosedependent gastrointestinal complaints such as nausea, diarrhea, and abdominal cramps. There is a black box warning regarding first trimester pregnancy loss and congenital malformations, in addition to increased infections and lymphoma risk.

There is even less literature concerning treatment of ACD and AD with MMF. However, a few studies do exist that indicate efficacy in the treatment of AD. The majority of participants in a restrospective chart review of 20 adults with refractory $\mathrm{AD}$ treated with MMF showed improvement, and $50 \%$ showed complete clearance [41]. Heller et al. reported 14 pediatric patients with AD treated with MMF where more than $50 \%$ attained $90 \%$ improvement without major adverse effects [42]. Waxweiler reported that two-thirds of AD patients treated with MMF showed significant improvement [43].

\section{Phototherapy (UVA, UVB, and Grenz)}

Narrowband ultraviolet light (UVB) has been shown experimentally in mice to suppress contact hypersensitivity reactions [44]. UVB has been used effectively in the management of ACD of the hands [45], and is a mainstay in the management of moderate to severe AD. Psoralen photochemotherapy (PUVA) is less commonly utilized now that UVB units are widely available, easier to use, and have less potential adverse effects. However, PUVA has been used to treat virtually all types of hand dermatitis, including ACD [46]. It allows for deeper penetration and may be more efficacious when compared to UVB treatment for hand dermatitis [47]. Topical PUVA therapy has been associated with a greater frequency in phototoxic reactions [48].

Superficial X-ray therapy and Grenz ray therapy (GRT) are two types of ionizing radiation that have been used to treat inflammatory skin conditions such as chronic hand dermatitis. While studies have shown combination superficial X-ray therapy and topical therapy is more efficacious than topical therapy alone for chronic hand eczema [49, 50], support for GRT has been mixed, with one study showing no benefit over placebo in chronic hand eczema [51]. However, a study of six subjects with patch-test-confirmed type IV hypersensitivity to nickel was able to demonstrate that GRT on the back prior to repeat patch testing could suppress the clinical manifestation of a positive patch test [52]. It has also been reported that while GRT may not improve irritant contact dermatitis [53], patients with ACD that are poorly responsive to topical corticosteroids may see an improvement with the combination of GRT and topical corticosteroids when compared to topical treatment alone [54, 55]. A cross-sectional survey mailed to patients treated with GRT between 1990 and 
2001 looked at efficacy and patient perception of GRT in patients with dermatoses refractory to other medical therapy. Of the patients with an eczematous dermatitis who responded to the survey, $71 \%$ felt that GRT significantly decreased the severity and discomfort of their disease. When looking at patients with the diagnosis of ACD, $72 \%$ of patients felt that GRT significantly decreased the severity and discomfort of their disease, and $77 \%$ of patients indicated they would use GRT again [56].

\section{Compliance with Ethical Standards}

\section{Conflict of Interest}

Michael P. Sheehan declares that he has no conflict of interest.

Human and Animal Rights and Informed Consent

This article does not contain any studies with human or animal subjects performed by any of the authors.

\section{References and Recommended Reading}

Papers of particular interest, published recently, have been

highlighted as:

- Of importance

- Of major importance

1. Marks J, Elsner P. Contact \& occupational dermatology. 9 3rd ed. St. Louis: Mosby; 2002. Print.

2. $\quad$ Rycroft RJG. "Chapter 21 Patch Testing." Textbook of Contact Dermatitis. Berlin: Springer; 2001. p. 435-68. Print.

3. Lachapelle JM. A proposed relevance scoring system for positive allergic patch test reactions: practical implications and limitations. Contact Dermatitis. 1997;36:3943.

4. Jamil WN, Erikssohn I, Lindberg M. How well is the outcome of patch testing remembered by the patients? A 10-year follow-up of testing with the Swedish baseline series at the Department of Dermatology in Orebro, Sweden. Contact Dermatitis. 2012;66(4):21520.

Excellent report highlighting the importance of patient education.

5. Sulzberger MB, Witten VH, Yaffe SN. Cortisone acetate administered orally in dermatologic therapy. Arch Dermatol Syphilol. 1951;64:573-8.

6. Sulzberger MB, Witten VH. The effect of topically applied compound F in selected dermatoses. J Invest Dermatol. 1952;19(2):101-2.

7. Stem R. The pattern of topical corticosteroid prescribing in the United States, 1989-1991. J Am Acad Dermatol. 1996;183-196.

8. Tadicherla S, Ross K, Shenefelt P, Fenske N. Topical corticosteroids in dermatology. J Drugs Dermatol. 2009;8(12):1093-105.

9. Jacob S, Steele T. Corticosteroid classes: a quick reference guide including patch test substances and cross reactivity. J Am Acad Dermatol. 2006;54(4):723-7.

10. Saary J, Qureshi R, Palda V, DeKoven J, Pratt M, Skotnicki-Grant S, et al. A systematic review of contact dermatitis treatment and prevention. J Am Acad Dermatol. 2005;53(5):845-55.

11. Hachem JP, De Paepe K, Vanpée E, et al. Efficacy of topical corticosteroids in nickel-induced contact allergy. Clin Exp Dermatol. 2002;27:47-50.

12. Parneix-Spake A, Goustas P, Green R. Eumovate (clobetasone butyrate) $0.05 \%$ cream with its moisturizing emollient base has better healing properties than hydrocortisone $1 \%$ cream: a study in nickel-induced contact dermatitis. J Dermatol Treat. 2001;12:191-7.

13. Vernon HJ, Olsen EA. A controlled trial of clobetasol propionate ointment $0.05 \%$ in the treatment of experimentally induced rhus dermatitis. J Am Acad Dermatol. 1990;23:829-32.

14. Cohen D, Heidary N. Treatment of irritant and allergic contact dermatitis. Dermatol Ther. 2004;17:334-40.

15. Lauerma AI, Stein BD, Homey B, et al. Topical FK 506: suppression of allergic and irritant contact dermatitis in the guine pig. Arch Dermatol Res. 1994;286:337.

16. Katsarou A, Makris M, Papagiannaki K, Lagogianni E, Tagka A, Kalogeromitros D. Tacrolimus $0.1 \%$ vs mometasone furoate topical treatment in allergic 
contact hand eczema: a prospective randomized clinical study. Eur J Dermatol. 2012;22(2):192-6.

Study highlights that Tacrolimus is a promising alternative therapy for contact dermatitis patients.

17. Katsarou A, Armenaka M, Vosynioti V, Lagogianni E, Kalogeromitros D, Katsambas A. Tacrolimus ointment $0.1 \%$ in the treatment of allergic contact eyelid dermatitis. J Eur Acad Dermatol Venereol. 2009;23(4):382-7.

18. Alomar A, Puig L, Gallardo CM, Valenzuela N. Topical tacrolimus $0.1 \%$ ointment (protopic) reverses nickel contact dermatitis elicited by allergen challenge to a similar degree to mometasone furoate $0.1 \%$ with greater suppression of late erythema. Contact Dermatitis. 2003;49:185-8.

19. Belsito D, Wilson DC, Warshaw E, Fowler J, Ehrlich A, Anderson $\mathrm{B}$, et al. A prospective randomized clinical trial of $0.1 \%$ tacrolimus ointment in a model of chronic allergic contact dermatitis. J Am Acad Dermatol. 2006;55(1):40-6.

20. Bhardwaj SS, Jaimes JP, Liu A, et al. A double-blind randomized placebo-controlled pilot study comparing topical immunomodulating agents and corticosteroids for treatment of experimentally induced nickel contact dermatitis. Dermatitis. 2007;18-26.

21. Black RJ. Vulval eczema associated with propolis sensitization from topical therapies treated successfully with pimecrolimus cream. Clin Exp Dermatol.

2005;30(1):91-2.

22. Bavandi A, Fahrngruber H, Aschauer H, Hartmann B, Meingassner JG, Kalthoff FS. Pimecrolimus and tacrolimus differ in their inhibition of lymphocyte activation during the sensitization phase of contact hypersensitivity. J Dermatol Sci. 2006;43(2):117-26.

23. Meingassner JG, Fahrngruber H, Bavandi A. Pimecrolimus inhibits the elicitation phase but does not suppress the sensitization phase in murine contact hypersensitivity, in contrast to tacrolimus and cyclosporine A. J Investig Dermatol. 2003;121(1):77-80.

24. Pereira U, Boulais N, Lebonvallet N, Pennec JP, Dorange G, Misery L. Mechanisms of the sensory effects of tacrolimus on the skin. Br J Dermatol. 2010;163(1):70-7.

25. Flori ML, Andreassi L. Patch tests after cyclosporin A treatment in hyperreactive patients. Contact Dermatitis. 1994;31(5):325.

26. Lakshmi C, Srinivas CR, Jayaraman A. Ciclosporin in parthenium dermatitis-a report of 2 cases. Contact Dermatitis. 2008;59(4):245-8.

27. Granlund H, Erkko P, Reitamo S. Long-term follow-up of eczema patients treated with cyclosporine. Acta Derm Venereol. 1998;78:40.

28. Roekevisch E, Spuls PI, Kuester D, Limpens J, Schmitt J. Efficacy and safety of systemic treatments for moderateto-severe atopic dermatitis: a systematic review. J Allergy Clin Immunol. 2014;133(2):429-38.

29. Munro CS, Levell NJ, Shuster S, Friedmann PS. Maintenance treatment with cyclosporin in atopic eczema. Br J Dermatol. 1994;130:376-80.
30. Sowden JM, Berth-Jones J, Ross JS, Motley RJ, Marks R, Finlay AY, et al. Double-blind, controlled, crossover study of cyclosporin in adults with severe refractory atopic dermatitis. Lancet. 1991;338:137-40.

31. van Joost T, Heule F, Korstanje M, van den Broek MJ, Stenveld HJ, van Vloten WA. Cyclosporin in atopic dermatitis: a multicentre placebo-controlled study. Br J Dermatol. 1994;130:634-40.

32. Wahlgren CF, Scheynius A, Hagermark O. Antipruritic effect of oral cyclosporine A in atopic dermatitis. Acta Derm Venereol. 1990;70:323-9.

33. De D, Sarangal R, Handa S. The comparative efficacy and safety of azathioprine vs methotrexate as steroidsparing agent in the treatment of airborne-contact dermatitis due to Parthenium. Indian J Dermatol Venereol Leprol. 2013;79(2):240-1.

34. Verma KK, Mahesh R, Srivastava P, Ramam M, Mukhopadhyaya AK. Azathioprine versus betamethasone for the treatment of parthenium dermatitis: a randomized controlled study. Indian J Dermatol Venereol Leprol. 2008;74(5):453-7.

35. Verma KK, Bansal A, Sethuraman G. Parthenium dermatitis treated with azathioprine weekly pulse doses. Indian J Dermatol Venereol Leprol. 2006;72(1):24-7.

36. Schram ME, Roekevisch E, Leeflang MM, et al. A randomized trial of methotrexate versus azathioprine for severe atopic eczema. J Allergy Clin Immunol. 2011;128:353-9.

37. Denby KS, Beck LA. Update on systemic therapies for atopic dermatitis. Curr Opin Allergy Clin Immunol. 2012;12(4):421-6.

38. Sharma V, Bhat R, Sethuraman G, Manchanda Y. Treatment of parthenium dermatitis with methotrexate. Contact Dermatitis. 2007;57(2):118-9.

39. Egan CA, Rallis TM, Meadows KP, et al. Low-dose oral methotrexate treatment for recalcitrant palmoplantar pompholyx. J Am Acad Dermatol. 1999;40:612-4.

40.• Wolverton SE. Comprehensive dermatologic drug therapy. 3rd ed. Edinburgh: Saunders/Elsevier; 2013. Print.

Excellent resource for detailed information regarding dermatologic therapy.

41. Murray ML, Cohen JB. Mycophenolate mofetil therapy for moderate to severe atopic dermatitis. Clin Exp Dermatol. 2007;32:23-7.

42. Heller M, Shin HT, Orlow SJ, et al. Mycophenolate mofetil for severe childhood atopic dermatitis: experience in 14 patients. Br J Dermatol. 2007;157:127-32.

43. Waxweiler WT, Agans R, Morrell DS. Systemic treatment of pediatric atopic dermatitis with azathioprine and mycophenolate mofetil. Pediatr Dermatol. 2011;28(6):689-94.

44. Shintani Y, Yasuda Y, Kobayashi K, Maeda A, Morita A. Narrowband ultraviolet B radiation suppresses contact hypersensitivity. Photodermatol Photoimmunol Photomed. 2008;24(1):32-7.

45. Mork NJ, Austad J. Short-wave ultraviolet light (UVB) treatment of allergic contact dermatitis of the hands. Acta Dermato Venereol. 1983;63:87-9. 
46. Warshaw E. Therapeutic options for chronic hand dermatitis. Dermatol Ther. 2004;17:240-50.

47. Rosen K, Mobacken H, Swanbeck G. Chronic eczematous dermatitis of the hands. a comparison of PUVA and UVB treatment. Acta Dermato Venereol. 1987;67:48-54.

48. Simons JR, Bohnen IJWE, Van Der Walk PGM. A leftright comparison of UVB phototherapy and topical photochemotherapy in bilateral chronic hand dermatitis after six weeks' treatment. Clin Exp Dermatol. 1997;22:7-10.

49. Fairris GM, Mack DP, Rowell NR. Superficial X-ray therapy in the treatment of constitutional eczema of the hands. Br J Dermatol. 1984;111:445-9.

50. King CM, Chalmers RJG. A double blind study of superficial radiotherapy in chronic palmar eczema. Br J Dermatol. 1984;111:451-4.

51. Cartwright PH, Rowell NR. Comparison of Grenz rays versus placebo in the treatment of chronic hand eczema. Br J Dermatol. 1987;117:73-6.
52. Lindelof B, Liden S, Lagerholm B. The effect of grenz rays on the expression of allergic contact dermatitis in man. Scand J Immunol. 1985;21:463-9.

53. Lindelof $\mathrm{B}$, Lindberg $\mathrm{M}$. The effect of grenz rays on irritant skin reactions in man. Acta Derm Venereol. 1987;67:128-32.

54. Lindelof B, Wrangsjo K, Liden S. A double-blind study of Grenz ray therapy in chronic eczema of the hands. $\mathrm{Br}$ J Dermatol. 1987;117:77-80.

55. Warner J, Ponciano C. Grenz ray therapy in the new millennium: still a valid treatment option? Dermatitis. 2008;19(2):73-80.

56. Schalock P, Zug K, Carter J, Dhar D, MacKenzie T. Efficacy and patient perception of Grenz ray therapy in the treatment of dermatoses refractory to other medical therapy. Dermatitis. 2008;19(2):90-4

57. Baeck M, Goossens A. Immediate and delayed allergic hypersensitivity to corticosteroids: practical guidelines. Contact Dermatitis. 2012;66(1):38-45. 